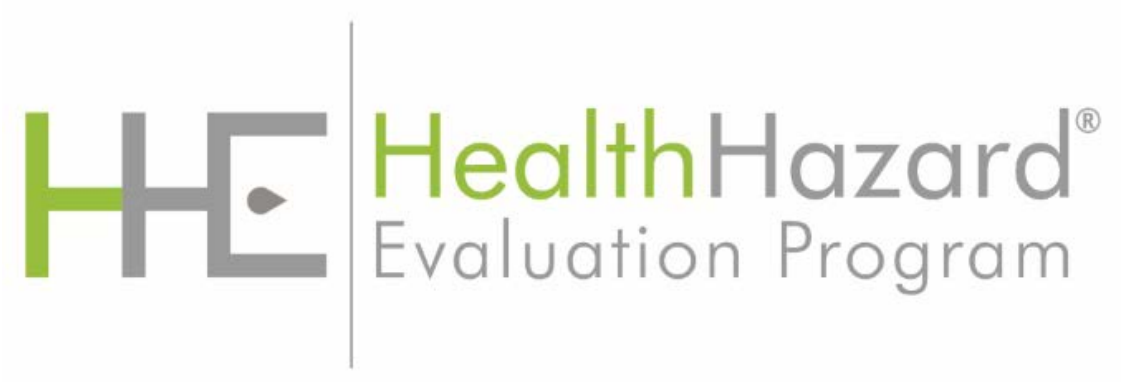

\title{
Evaluation of Exposures and Health Effects in Fire Fighters Following Response to a Chemic al Fire
}

HHE Report No. 2018-0080-3350

May 2019

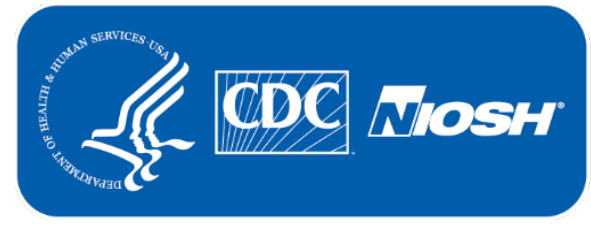




\section{Authors: Judith Eisenberg, MD, MS}

\section{R. Reid Harvey, DVM, MPH}

\section{Karl D. Feldmann, MS, CIH}

Analytical Support: Kathleen Fedan

Desktop Publisher: Jennifer Tyrawski

Medical Field Assistance: Nicole Edwards, Laurel Harduar-Morano, and Brian Tift

Data Support: Nicole Edwards and Brian Tift

Keywords: North American Industry Classification System (NAICS) 922160 (Fire Protection)

Rhode Island, Chemical Fire, Chemical Exposures, Pulmonary Irritant, Tier II report, Hazardous Waste Operations and Emergency Response (HAZWOPER)

\section{Disclaimer}

The Health Hazard Evaluation Program investigates possible health hazards in the workplace under the authority of the Occupational Safety and Health Act of 1970 [29 USC 669a(6)]. The Health Hazard Evaluation Program also provides, upon request, technical assistance to federal, state, and local agencies to investigate occupational health hazards and to prevent occupational disease or injury. Regulations guiding the Program can be found in Title 42, Code of Federal Regulations, Part 85; Requests for Health Hazard Evaluations [42 CFR Part 85].

\section{Availability of Report}

Copies of this report have been sent to the employer, employees, and union. The state and local health department and the Occupational Safety and Health Administration Regional Office have also received a copy. This report is not copyrighted and may be freely reproduced.

\section{Recommended Citation}

NIOSH [2019]. Evaluation of exposures and health effects in fire fighters following response to a chemical fire. By Eisenberg J, Harvey RR, Feldmann KD. Cincinnati, OH: U.S. Department of Health and Human Services, Centers for Disease Control and Prevention, National Institute for Occupational Safety and Health, Health Hazard Evaluation Report 2018-0080-3350, https://www.cdc.gov/niosh/hhe/reports/pdfs/2018-0080-3350.pdf. 


\section{Table of Contents}

\section{Main Report}

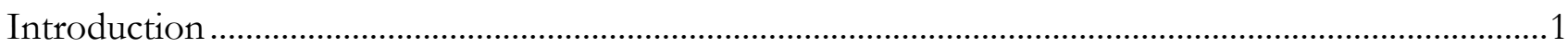

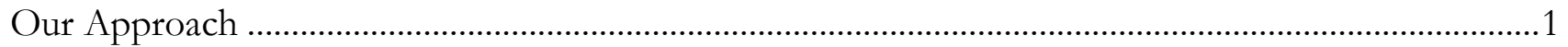

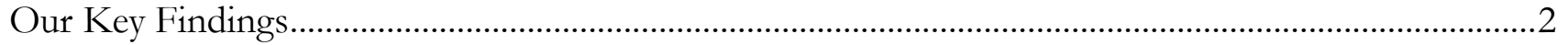

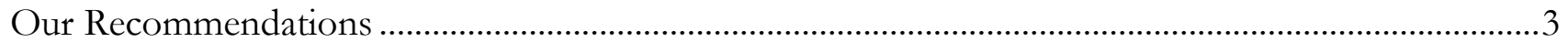

\section{Supporting Technical Information}

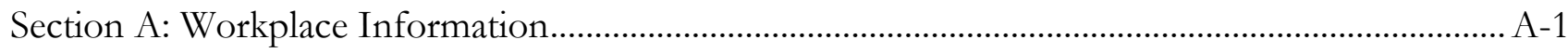

Incident Location ...............................................................................................................

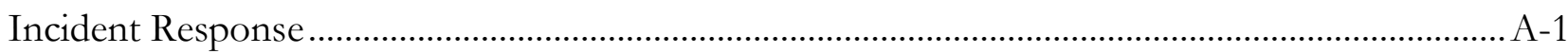

Section B: Methods, Results, and Discussion .......................................................................... B-1

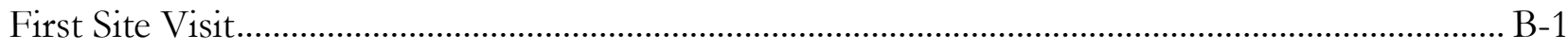

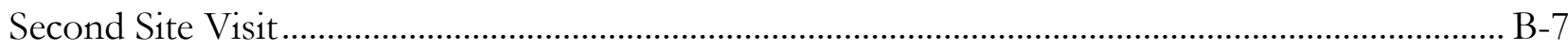

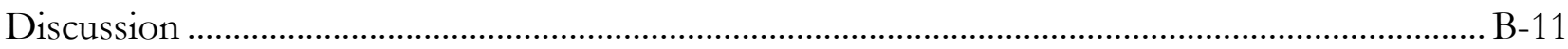

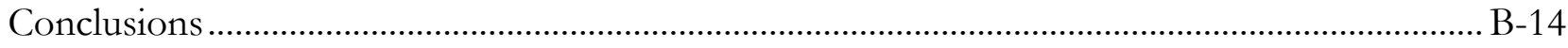

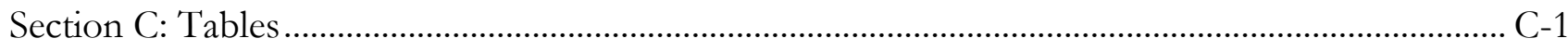

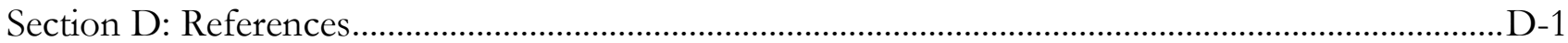


This page left intentionally blank 


\section{Introduction}

\section{Request}

The national union representing fire fighters requested assistance after a municipal fire department responded to a fire at a chemical manufacturer and distributor (Company A). The fire occurred in January 2018. The request concerned chemical exposures these fire fighters may have experienced during their response activities and asked for guidance on long-term medical monitoring for those who participated in this response.

\section{Incident}

- The fire department responded to an automated fire alarm at Company A.

- Fire fighters entered the building and found an active fire burning in a chemical disposal vat. It was unclear what was in the vat due to missing or incomplete labeling and inventory documentation.

- Hazardous material (HAZMAT) crews responded to the incident.

- Some fire fighters became ill while inside the building and others upon leaving the building.

- While most responders fully recovered, some responding fire fighters had persistent symptoms that they associated with their participation in the chemical fire response.

\section{To learn more about the workplace, go to Section A in the Supporting Technical Information}

\section{Our Approach}

We conducted two site visits. During both site visits, all fire fighters from this department who responded to the chemical fire were invited to participate. During the first visit in March 2018 we

- Conducted confidential medical interviews with 46 fire fighters. Interviews covered work history, pre-existing medical conditions, role(s) filled during chemical fire response, number of building entries made, development and duration of health effects they associated with their participation in the chemical fire response.

- Reviewed fire fighter medical records and departmental incident reports.

- Reviewed the fire department's standard operating procedures including HAZMAT and decontamination protocols.

- Reviewed chemical inventory records for Company A.

- Reviewed laboratory analysis of solid and liquid samples collected at the fire location. 
- Reviewed fire fighters' mandatory annual spirometry and the additional spirometry results conducted following the chemical fire.

During the second visit in May 2018, we:

- Administered a health questionnaire to 47 fire fighters with questions about respiratory and other symptoms, medical diagnoses such asthma and other medical conditions, work history, and personal protective equipment use including during the response to the chemical fire.

- Performed spirometry and other breathing tests on 46 fire fighters.

- Consulted with the fire department's occupational health provider whose staff performed the department's annual and the post-fire response spirometry testing.

To learn more about our methods, go to Section B in the Supporting Technical Information

\section{Our Key Findings}

\section{Based on available information we cannot determine the exact exposures fire fighters encountered during the response.}

The fire department determined an alkaline substance was present at Company A. However, we were not able to identify all chemicals that may have been present due to:

- Incomplete or missing chemical labeling of containers at Company A.

- An incomplete Tier II chemical inventory list from Company A.

- Limited post-event sampling of residual solid and liquid remnants at Company A.

- The potential for unknown chemical byproducts as a result of the fire or from chemical reaction with the water used for fire suppression.

Many fire fighters who participated in the response reported symptoms during or shortly after the response. Most fire fighters who had symptoms related to the response fully recovered, although some fire fighters had persistent symptoms after 4 months.

Department records showed that 65 fire fighters responded to the chemical fire. Of those responders, 16 were transported to emergency departments from the scene. All responding fire fighters were invited to participate in both NIOSH site visits.

- 46 fire fighters participated in interviews during the first site visit about 1 month after the fire.

o 26 reported symptoms that started while on scene at the chemical fire or shortly afterwards. The most common immediate symptoms reported were a dry cough shortness of breath, fatigue, and throat irritation. 
o 13 of the original 26 fire fighters who reported immediate symptoms stated they still had ongoing symptoms. Their most frequently reported symptoms were cough, shortness of breath, and throat irritation.

- 47 fire fighters participated during the second site visit about 4 months after the fire.

o Seven of the 47 fire fighters reported ongoing respiratory symptoms, including cough, trouble breathing, wheeze, chest tightness, being awoken by cough, or being awoken by shortness of breath.

o One of 46 fire fighters who performed spirometry testing conducted by NIOSH during the second site visit had abnormal results.

The department's action of performing spirometry after the response was appropriate due to the predominance of respiratory symptoms reported among responding fire fighters but future spirometry testing and the existing medical monitoring program can be improved.

- The occupational health provider has the expertise and training required to identify and correct a procedural testing error that occurred, and is committed to making the necessary equipment upgrades to do so.

To learn more about our results, go to Section B in the Supporting Technical Information

\section{Our Recommendations}

\section{Recommendation 1: Audit practices and procedures regarding chemical fire responses and HAZMAT situations.}

Why? Following department HAZMAT and personal protective equipment protocols protects fire fighters engaged in primary fire suppression, fire fighters serving as emergency medical staff, fire ground standby, and other support staff on-site.

How? At your workplace, we recommend these specific actions:

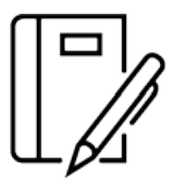

Continue to ensure that department standard operating procedures for chemical fire responses and HAZMAT situations comply with National Fire Protection Agency (NFPA) guidelines:

- Insure that only fire fighters wearing appropriate gear enter an identified HAZMAT situation. 
- Establish a decontamination line and a stand-by extraction team prior to firefighters entering an identified HAZMAT situation.

- Follow proper decontamination procedures (e.g., removing all contaminated bunker gear and remaining on supplied air until the last decontamination step is completed).

- Conduct after-action evaluations of existing safety and HAZMAT protocols to determine if training or protocols need to be updated.

- Periodically review and update written procedures. NFPA sets fire fighter standards for personal protective equipment, safe entry procedures, and decontamination procedures in the following documents:

o NFPA 1521 Standard for Fire Department Safety Officer 2008 Edition

o NFTA 1584 Standard on the Rehabilitation Process for Members During Emergency Operations and Training Exercises 2015 Edition

\section{Recommendation 2: Further improve your medical surveillance program.}

Why? The purpose of a medical surveillance program is to identify fire fighters who have been exposed to substances known to pose a risk of potentially serious health conditions, such as reactive airway dysfunction syndrome (RADS) or work-related asthma, so that treatment is promptly initiated and interventions made to prevent similar exposures occurring to co-workers.

\section{How? At your workplace, we recommend these specific actions:}

\section{Work with your occupational health provider to improve the spirometry testing for fire fighters.}

- Request the provider to start quality control of spirometry testing by reviewing the test results as they are done to immediately identify and correct testing procedure errors.

This would be followed by repeating the spirometry so a usable result is obtained before the fire fighter leaves the testing area.

- Encourage the occupational health provider to acquire a computer monitor to display test results from the handheld flow spirometer. The display on the handheld unit is quite small making it difficult for technicians to see when a testing error message is displayed, which may cause occurrence of the error to be missed. 


\section{Continue annual spirometry and evaluate fire fighters' spirometry results over time to identify drops in lung function greater than would be expected due to normal aging.}

- Evaluate spirometry results at the time of testing to look for current abnormalities and compare with past spirometry test results to identify abnormal declines in lung function over time. NIOSH offers free software (SPIROLA) that can assist in evaluating spirometry data over time (https://www.cdc.gov/niosh/topics/spirometry/spirolasoftware.html).

- Refer fire fighters who show a greater than expected drop in lung function to a pulmonologist for further evaluation and treatment.

o Attempt to identify any possible exposures that might account for the abnormal drop in lung function. If a potential causative exposure is found, the department can work on reducing or removing the exposure to protect other fire fighters.

\section{Monitor respiratory symptoms annually as part of the medical surveillance program.}

- Add respiratory symptom questionnaires to the annual respirator fit testing procedures.

- New or persistent respiratory symptoms should prompt additional medical evaluation.

o If multiple fire fighters report onset of new respiratory symptoms, the department should conduct a review of incident logs to see if there is a common factor among these fire fighters (e.g., response to a specific fire location, potential exposures at multiple locations). This would help the department to identify possible sentinel events and prompt intervention to prevent similar exposures in other fire fighters.

- Combining review of annual questionnaire responses with review of annual spirometry test results may help in the investigation of the possible causes if fire fighters showed abnormal spirometry results while also reporting new onset of respiratory symptoms.

Fire fighters with persistent symptoms, or with abnormal spirometry, should continue to seek appropriate follow-up with their healthcare providers. 
This page left intentionally blank 


\section{Supporting Technic al Information}

Evaluation of Exposures and Health Effects in Fire Fighters Following Response to a Chemic al Fire HHE Report No. 2018-0080-3350

May 2019 


\section{Section A: Workplace Information}

The following overview of the incident site and response were obtained from interviews with responding fire fighters and department staff; our review of department records of the incident; and discussions with involved parties. We received conflicting reports about some of the details of the response; therefore, we only present a limited amount of incident response information.

\section{Incident Location}

In January 2018, the fire department responded to an automated fire alarm at a building that housed Company A and another unrelated business. The building was described in a state Fire Board of Appeals Report as "an existing 1-story with basement, industrial occupancy consisting of approximately 18,770 square feet." At the time of the fire, Company A was primarily performing chemical mixing and distribution work at this location.

\section{Incident Response}

The fire fighters entering Company A found an active fire in a chemical disposal vat and noted that the sprinklers had activated. Since the initial entry teams reported no evidence of an explosion or other ongoing visible chemical reaction between the contents of the vat and the sprinkler water, fire fighters fully extinguished the fire with water and the fire was contained. It was unclear what was in the vat and directly involved in the fire. Company A's owner was interviewed on-site by the department's fire investigator, but no additional information regarding the substances in the vat was available. Entry teams reported that litmus paper attached to their turnout gear indicated an alkaline substance was present.

Some of fire fighters involved in the response reported becoming ill inside the building, and others became ill upon leaving the building. Several fire fighters experienced a metallic taste in their mouth. One fire firefighter developed shortness of breath, chest pain, and cough prompting immediate on-scene care by the standby EMS units. An additional fire fighter serving as an emergency medical provider became ill during transport of a fellow fire fighter to a local emergency department (ED). Another fire fighter who was not on-scene, reported onset of symptoms the day after the fire when they were doing routine cleaning and maintenance on equipment that had been used in the response the previous day.

In total, 16 fire fighters were transported to local EDs from the scene. No fire fighters were hospitalized. All firefighters who were on location at the chemical fire were asked to complete an incident form to document their presence at the response regardless if they developed symptoms after the response that they felt were related to their presence at the fire location. 


\section{Section B: Methods, Results, and Discussion}

The objectives of our evaluation were to:

- Determine what chemicals fire fighters may have been exposed to.

- Quantify the number of fire fighters who developed immediate and delayed symptoms they felt were related to their participation in the response to the fire at Company $\mathrm{A}$ and determine if these symptoms were consistent with exposure to specific chemical(s).

- Determine if fire fighters had abnormal lung function.

- Compare fire fighter's prevalence of respiratory symptoms and healthcare provider-diagnosed asthma and chronic bronchitis to expected levels based on general population values.

- Evaluate the spirometry data provided by the fire department's occupational health provider for quality.

- Advise the fire department if any additional employee medical monitoring may be indicated for fire fighters who participated in the response to the fire at Company A.

- Determine if changes to department entry procedures, PPE use, or decontamination procedures may be indicated.

All 65 fire fighters who participated in the January 2018, chemical fire response were invited to participate in both NIOSH site visits. The first site visit occurred March 2018 and the second site visit was conducted May-June 2018.

\section{First Site Visit}

\section{Method: Chemical Exposure Assessment}

We reviewed the following documents:

- Company A Tier II chemical inventory records

- Fire Safety Code Board of Appeals documents

- Analysis of solid and liquid samples collected at the incident and of turnout gear

- Fire department after-action report and standard operating procedures

Results: Chemical Exposure Assessment

Inventory Records

The local Occupational Safety and Health Administration (OSHA) office provided us the most recent chemical inventory list that Company A submitted in 2017. Federal legislation by the U.S.

Environmental Protection Agency under the "Emergency Planning and Community Right to Know" [U.S. Code Title 42 Chapter 116] requires businesses to submit an inventory of chemicals stored and used on site. These Tier II inventory records should include each chemical present, an estimate of 
average daily quantity used, the total amount of each chemical stored on site, and the location on-site and manner in which it is stored.

Initial entry teams reported that labeling was missing or incomplete on many of the containers they observed in Company A's portion of the building. Additionally, there was no documentation describing Company A's chemical waste disposal procedures or any documentation regarding what substances may have been in the vat prior to the fire. Company A was noted to be non-compliant by the local Department of Environmental Protection in providing their Tier II inventory. This inventory was reportedly not available to fire fighters or HAZMAT crews at the time of the fire response and was obtained from the owner after the fire response was concluded.

\section{Fire Safety Board of Appeals Document}

A report from the local Fire Safety Code Board of Appeals dated 2017 classified Company A as a "high hazard" facility due to the lack of both an automated fire alarm and automated sprinkler fire suppression system. The board gave the company 150 days to install both systems, which reportedly was completed just prior to the fire. However, this document also stated that the company was required to remove "all fueled equipment" from the facility within two weeks. The Board's letter did not define what chemicals they considered to be "fueled equipment."

\section{Analysis of Samples Collected by Abatement Company}

Company A hired an abatement company clean up after the fire. They collected one liquid and one solid sample from the site 2 days after the fire. The analyses of these samples reported the following:

- "Water Sample": This sample was collected from the fire suppression wastewater. Chromium, copper, lead, nickel, selenium, and zinc were present. Small amounts of mercury and cyanide were also found. The laboratory reported the $\mathrm{pH}$ of the water sample was 13.4.

- "Solid Sample": This sample was collected from residue remaining in the disposal vat where the fire originated. Chloride, nitrogen (including nitrogen in the form of nitrates and nitrites), and sulfate were present along with small amounts of arsenic, chromium, and copper. The laboratory reported the $\mathrm{pH}$ of the solid sample was 12.8 .

Additional details of these samples are show in Section C, Table 1.

\section{Analysis of Contaminated Gear}

During the response, the HAZMAT entry teams attached litmus paper strips to their Level A protective suits. Litmus paper changes color following contact with acid (low $\mathrm{pH}$ ) or alkaline (high $\mathrm{pH}$ ) substances. All the strips had color changes indicating the presence of highly alkaline substances $(\mathrm{pH} \approx$ 12). A similar level of alkalinity was found on fire fighter gear prior to decontamination. A crystalline substance formed on contaminated gear that had been stored on-site overnight. The local Department of Environmental Management analyzed the crystals. They were found to contain selenium dioxide.

\section{Fire Department After-Action Report and Standard Operating Procedures}

The fire department after-action report and standard operating procedures (SOP) were discussed with the fire department and fire fighters during the course of the HHE. 


\section{Method: Confidential Medical Interviews}

All 65 fire fighters who participated in the fire response at Company A were invited to participate in confidential medical interviews. The interviews included questions about (1) basic demographic data, (2) work history, (3) prior medical diagnoses, (4) tasks conducted during their participation in the response to the fire at Company A, (5) any symptoms that started while at the scene, and (6) any current symptoms they associated with that fire response. If participants reported previous or ongoing symptoms and had sought medical evaluation for these symptoms, participants were asked to sign a medical record release form so we could obtain and review those records.

\section{Results: Confidential Medical Interviews}

In total, 46 (71\%) of 65 invited fire fighters participated in the confidential medical interviews. The majority (98\%) of interview participants were male. The median age was 47 years (range: $26-66$ years). The median total years as a fire fighter (any crew, paid or volunteer) was 23.5 years (range: 1.342 years), and the median duration of employment at the CFD was 20 years (range: $1.3-33$ years). Thirty $(65 \%)$ interviewed firefighters were HAZMAT certified.

Twenty-six (57\%) fire fighters reported one or more health symptoms that they believed were related to their participation in the January response. Seventeen (65\%) of the 26 made at least one building entry. For those who reported at least one building entry, the average time reported to be spent inside the building was 11 minutes (range: 30 seconds to 30 minutes). The most common symptoms reported after exiting were a dry cough $(\mathrm{n}=12)$ followed by shortness of breath, fatigue/malaise, and throat irritation ( $\mathrm{n}=6$ for all 3 of these symptoms). The category of throat irritation also included descriptions of throat tickle, sore throat, a need to clear throat, and raspy voice.

Of the 26 fire fighters who reported continuing health symptoms that they associated with their participation in the Company A response, the most common symptoms was cough with 12 (46\%) reports. There were six (23\%) reports each of shortness of breath, fatigue/malaise, and throat irritation (same inclusion of other related descriptions as noted above). Thirteen (50\%) fire fighters who reported symptoms since the day of the chemical fire stated that they were still having those symptoms. Ten of these $13(77 \%)$ stated that they had missed at least one day of work due to these symptoms. Four reported being out of work more than 30 days due to these symptoms.

Nineteen of the 46 interviewed fire fighters reported performing tasks on scene that did not require them to enter the building. These tasks included (1) spraying water from hose lines through windows, (2) helping with HAZMAT crew dress out, (3) staffing decontamination lines, (4) directing traffic, (5) investigating the fire, and (6) providing medical support to EMS ambulance units. It is standard protocol for fire departments to have EMS units on standby at an active fire scene to care for fire fighters and fire victims. These units are staffed by department fire fighters with emergency medical technician (EMT) credentials. Of the 19 fire fighters who were on scene but did not enter the building, four $(21 \%)$ reported developing symptoms while outside the building, including dry cough $(\mathrm{n}=4)$ and metallic taste $(n=2)$. The average total time on scene for these 19 fire fighters was reported as 431 minutes (range: 55-570 minutes), excluding one participant who only reported five minutes on scene as they were acting as EMS to transport the ill fire fighter. One fire fighter was not on scene at all 
during the fire response but reported that their exposure occurred when handling equipment used onscene the day after the fire.

\section{Method: Medical Document Review}

We reviewed the following documents:

- Fire Department's Occupational Injury Reports related to the incident.

- ED records for those fire fighters who were transported from the scene of the chemical fire to local hospitals for evaluation

- Medical records from other healthcare providers that fire fighters visited for health issues believed to be related to the response.

- Result of blood cyanide analyses from samples drawn in the ED for 16 fire fighters analyzed by the state Department of Health and one blood cyanide level analyzed by a local hospital laboratory.

- Annual spirometry results for 2016 and 2017 and post-event spirometry one week after the fire conducted by department occupational health provider.

\section{Results: Medical Document Review}

\section{Departmental Occupational Injury Reports}

Sixty-five fire fighters completed injury reports documenting their participation in the fire response at Company A. Senior officers in the department asked all participants in the response to the fire at Company A to complete an injury report form to document their presence on scene in the event they developed symptoms in the future that may be related to on-scene exposures. Review of these reports showed that $36(55 \%)$ of 65 responders experienced at least one symptom they felt was related to their role in the fire response. The most common symptoms reported were 30 reports each of cough and shortness of breath/other breathing issues followed by a metallic taste in their mouth $(\mathrm{n}=20)$ and dry/scratchy/irritated throat $(\mathrm{n}=12)$. The remaining $29(45 \%)$ fire fighters did not list any current symptoms on their injury reports.

\section{Emergency Department Records of Fire Fighters}

Sixteen fire fighters were evaluated at local EDs the night of the fire; all were discharged after observation. One fire fighter was diagnosed with "possible smoke inhalation" while the remainder were diagnosed with "chemical exposure." The diagnosis of chemical exposure was based on the related histories of present illness and not due to objective findings of a specific chemical exposure.

One fire fighter reported to ED staff that on entry to Company A's part of the building, they saw broken bottles with labels that listed cyanide and nitric acid ingredients and a white powder on the floor. This fire fighter stated they were not on supplied air at the time. They reported a metallic taste in their mouth followed by shortness of breath. On spotting the powder on the floor, they immediately exited the building, donned supplied air, and re-entered the building with a hose line to continue fire suppression. Almost immediately upon re-entering the building, they reported experiencing chest pain and nausea in addition to the shortness of breath. At this time, they exited the building and were 
brought to the on-site medical team for care. The EMS team removed this fire fighter's mask, supplied air tank, and bunker coat, and provided oxygen to address the fire fighters respiratory distress. Triage notes indicate that although their heart rate was elevated, the fire fighter had a normal lung exam and blood oxygen levels on room air. ED records showed that the cyanide antidote was administered to this fire fighter on arrival based on their evident respiratory distress and reports of encountering chemical labels listing cyanide.

Within two hours of arrival to the ED, it was noted that this fire fighter was "resting comfortably in no acute respiratory distress." Their heart rate had normalized and a chest x-ray obtained 30 minutes after ED arrival was read as normal. Consultation with Poison Control noted that they agreed with discharge plan. A blood cyanide level analyzed by the hospital laboratory revealed a level of 11 micrograms per deciliter $(\mu \mathrm{g} / \mathrm{dL})$, which was within the lab's reported reference range $0-20 \mu \mathrm{g} / \mathrm{dL}$.

ED records indicate six responding fire fighters were given the cyanide antidote presumptively based on their reports of cyanide listing on a bottle label and symptoms on presentation. One fire fighter presented to the ED two days after the fire with "chest burning." Records noted that Poison Control requested that a chest x-ray be ordered to "rule out pneumonitis from nickel exposure." The chest x-ray was obtained and read as normal. Cardiac markers and an EKG were also obtained and read as normal. The fire fighter was then discharged home. The records do not indicate the source of the concern regarding nickel exposure.

Additional ED records showed that one fire fighter had an abnormal chest radiograph but no shortness of breath or abnormal findings on pulmonary exam. A repeat chest radiograph about two weeks later was normal. Two fire fighters had greenish discoloration on their hands, but an evaluation by the ED burn team did not find evidence of chemical or thermal burns on either fire fighter. Neither had records documenting they had followed up with the burn clinic. During the confidential interviews, they both reported that the skin discoloration had faded within days for both so they did not feel a visit to the burn clinic was necessary.

One fire fighter who participated in the confidential interviews was not on scene the night of the chemical fire but reported handling equipment used during the response as part of a routine equipment check three days after the event. This fire fighter reported onset of symptoms of shortness of breath, cough, nausea, and weakness immediately after handling these tools and was evaluated in an ED six days after the event. This fire fighter was discharged later that day with a diagnosis of viral syndrome.

\section{Additional Medical Records}

We reviewed additional medical records of 14 interviewed fire fighters who reported they had been evaluated by other healthcare providers for symptoms they felt were related to their participation in the chemical fire response. Two fire fighters were evaluated by a pulmonologist and one was given a diagnosis that related respiratory symptoms to possible chemical exposure during the response. The other fire fighter was diagnosed with worsening of pre-existing asthma, but the cause was not determined. A different fire fighter was evaluated at an ED the night of the response for respiratory symptoms that resolved prior to being discharged. This fire fighter developed nausea and vomiting two days later. They reported these symptoms lasted for about two weeks. This fire fighter had multiple visits to their primary care provider, but no reason was found for these symptoms before they resolved. 
One fire fighter reported developing severe acne on their face and back of their neck. Records obtained from their primary care provider only noted a single visit. There was no mention of acne on the physical exam, nor was it included in the assessment and/or plan from that visit.

\section{Cyanide Testing Conducted by the Rhode Island Department of Health}

Since some responders had reported seeing containers inside the facility with cyanide-containing components listed on container labeling; the state health department obtained blood samples from 16 fire fighters to test them for cyanide. All 16 samples had "nondetectable" serum cyanide levels. These laboratory reports noted that a nondetectable result could indicate that the "cyanide concentration was either not quantifiable or was present below the reporting limit." The reporting limits for this test were listed as 25 parts per billion (ppb)-2,500 ppb. This laboratory noted a reference level for "normal" as $<100 \mathrm{ppb}$ with a comment that no symptoms are expected with blood cyanide levels less than $500 \mathrm{ppb}$. It should be noted that there is no physiological role for cyanide in the body so the laboratory's use of "normal" in reporting their test results may reflect a level above which they determined that cyanide poisoning related symptoms may be expected to occur. All 16 reports note the collection date as the day of the fire response at Company A.

\section{Method: Review of Spirometry Testing from Occupational Health Provider}

We reviewed 136 spirometry tests from 52 fire fighters who received annual spirometry testing through the fire department's occupational health provider. Most fire fighters involved in the Company A response received an additional spirometry test approximately one week after the incident. This fire department provided reports of the post-fire testing and the two most recent annual spirometry tests available (2016 and 2017 for most fire fighters) for our review. The provider stated that all their spirometry technicians were NIOSH-certified spirometry technicians.

\section{Results: Review of Spirometry Testing from Occupational Health Provider}

Overall, it appeared that the fire fighters' efforts on the testing were above average. These fire fighters gave very good and consistent efforts on these tests, with sharp peaks at the beginning of the maneuvers. However, we found that many of the tests contained trials of unusually long length, and some of these contained "positive zero flow errors." This is an error in how the technician conducted the test. It occurs when the spirometry equipment detects airflow before the subject begins the maneuver. This can happen when a subject rapidly moves the spirometer mouthpiece to their mouth to begin the maneuver or if testing is done in a room with a lot of air movement (i.e., if a fan is near the testing station). Results obtained by spirometry tests with positive zero flow errors cannot be interpreted because the reported values are erroneously high.

The majority of the spirometry tests also appear to have findings that indicate other errors in how the tests were conducted. These errors demonstrated that the fire fighters reached plateaus (met end-of-test criteria) well before the maneuver terminated. We cannot determine if this was due to technician(s) coaching the fire fighter to stay on the mouthpiece longer than was necessary, or if the technician(s) had not notified the software that the test had ended, and the equipment continued to collect data after the maneuver was actually terminated. Either type of procedural error has a serious impact as their presence means that the test results containing them cannot be interpreted with confidence. If a healthcare 
provider cannot have confidence in test results due to error in how the test was conducted, then they cannot use the results of those tests to make decisions regarding that person's medical care.

\section{Second Site Visit}

We invited all fire fighters who were involved in the January 2018 chemical fire response to participate in the medical survey conducted at the department's main fire station during the second NIOSH visit in May 2018, about four months after the chemical fire. During this visit, we administered a medical and fire response questionnaire, and performed quantification of exhaled nitric oxide, impulse oscillometry, and spirometry. When indicated, NIOSH technicians repeated the standard spirometry and impulse oscillometry following administration of a bronchodilator. We mailed participants their individual reports explaining their breathing test results and recommended each participant provide their information to their personal physician.

\section{Method: Questionnaire}

We used an interviewer-administered computerized questionnaire to ascertain symptoms and diagnoses, fire response tasks and PPE use, and cigarette smoking history. Questions on respiratory health were derived from five standardized questionnaires:

- The European Community Respiratory Health Survey [Burney et al. 1994; ECRHS 2014]

- The American Thoracic Society adult respiratory questionnaire (ATS-DLD-78) [Ferris 1978]

- The International Union Against Tuberculosis and Lung Disease [Burney and Chinn 1987; Burney et al. 1989]

- The Third National Health and Nutrition Examination Survey (NHANES III) [Centers for Disease Control and Prevention 1996]

- NHANES 2007-2012 questionnaires [Centers for Disease Control and Prevention 2018].

Some of the questions appeared on more than one of the standardized questionnaires. We also supplemented our questionnaire with additional gastrointestinal and dermatologic symptoms questions based on findings from the March 2018 site visit.

We calculated frequencies and standardized morbidity ratios (SMRs) and their associated 95\% confidence intervals (CIs) using SAS version 9.4. The SMRs compared prevalences of symptoms and spirometry abnormalities among participants to expected prevalences of a sample of the general population reflected in the NHANES III (1988-1994, symptom data) and NHANES 2007-2012 (symptom data), adjusting for sex, race/ethnicity, age (less than 40 years old or 40 years or greater), and cigarette smoking categories (ever/never). NHANES is a program of studies designed to assess the health and nutritional status of adults and children in the United States. This survey includes data obtained from interviews and physical examination that also provide samples for biological testing for a long list of exposures. The program is managed by the National Center for Health Statistics, which is a part of the U.S. Centers for Disease Control and Prevention. Survey data can be publically accessed at https://www.cdc.gov/nchs/nhanes/index.htm. For comparisons to the U.S. population, we used the most recent NHANES survey available for the specific comparisons. 


\section{Results: Questionnaire}

Forty-seven (72\%) of 65 fire fighters completed the questionnaire administered during the May 2018 site visit. Most were male (98\%) and white (98\%), with a median age of 47 years (range: $27-59$ years). Median tenure with the current fire department was 16 years (range: 1-38 years). Eleven (25\%) participants were current or former smokers. Thirty-eight of the $46(83 \%)$ participants in the confidential medical interviews conducted during the first site visit also participated in the questionnaire and testing conducted during the second site visit.

Section C, Table 3 lists the prevalence of symptoms over three periods; the last 12 months, beginning during or shortly following the fire response, and ongoing at the time of the medical survey. Cough (43\%), trouble breathing (17\%), wheeze (13\%), and being awoken by cough $(13 \%)$ were the most common respiratory symptoms fire fighters reported developing during or shortly following the fire response. At the time of the survey, ongoing cough and trouble breathing were reported by four $(9 \%)$ fire fighters; ongoing wheeze and being awoken by cough were reported by one (2\%) fire fighter. Ongoing chest tightness and being awoken by shortness of breath were also reported by one $(2 \%)$ fire fighter each.

Fatigue, throat irritation, headaches, or skin symptoms that began during or shortly following the fire response were reported by $30 \%, 28 \%, 17 \%$, and 15\% of fire fighters, respectively. For those fire fighters who reported their symptoms began during or shortly following the response, eight (17\%) reported ongoing fatigue, five (11\%) reported ongoing headaches, four $(9 \%)$ reported ongoing skin symptoms, and three $(6 \%)$ reported ongoing throat irritation.

Gastrointestinal symptoms that began during or shortly following the response included diarrhea (23\%), nausea $(19 \%)$, and vomiting (3\%). Ongoing gastrointestinal symptoms at the time of the second site visit was reported by seven (15\%) fire fighters, and ongoing nausea was reported by two (4\%) fire fighters. Twenty (43\%) fire fighters reported a metallic taste during or shortly following the fire response that lasted for a median of 24 hours (range: 1-192 hours). Six (13\%) fire fighters reported a burning sensation that lasted a median 1.3 hours (range: $0.5-48$ hours). Two (4\%) fire fighters reported green skin discoloration that lasted a median 56 hours (range: 3-108 hours). Fire fighters reported being diagnosed with the following conditions since the fire: sinusitis, pneumonia, reactive airways dysfunction syndrome (RADS), tracheobronchomalacia, hypertension, and inflammatory bowel disease.

When possible, we compared the prevalences for symptoms and diagnoses reported by fire fighters to the general U.S. population. The SMR for wheeze during the year was 3.4. The SMR for ever receiving a physician diagnosis of asthma and current asthma diagnosis were elevated at 1.9 and 2.8, respectively. Prevalences for other symptoms and diagnoses were not elevated in comparison to the general U.S. population, adjusted for age distribution, race/ethnicity, sex, and smoking history.

\section{Methods: Pulmonary Function Testing Conducted by NIOSH}

\section{Spirometry}

Spirometry determines a person's ability to move air out of their lungs. We used a volume spirometer (dry rolling seal spirometer) to measure exhaled air volume and flow rates. We compared these values with expected normal values. The test included three measurements or calculations: 
- Forced vital capacity (FVC), (the total amount of air the participant can forcefully blow out after taking a deep breath)

- $\mathrm{FEV}_{1}$ (the amount of air that the participant can blow out in the first second of exhaling)

- The ratio of $\mathrm{FEV}_{1}$ to FVC. We calculate this ratio to aid in the interpretation of obstructive and restrictive patterns.

We used American Thoracic Society criteria for acceptability and repeatability [Miller et al. 2005].

We used equations for predicted values and lower limits of normal derived from NHANES III data to define abnormal spirometry [Hankinson et al. 1999].

We used the following definitions for the common patterns seen on spirometric testing:

- Obstructive pattern has an $\mathrm{FEV}_{1} / \mathrm{FVC}$ ratio less than the lower limit of normal with $\mathrm{FEV}_{1}$ less than the lower limit of normal

- Restrictive pattern showed a normal $\mathrm{FEV}_{1} / \mathrm{FVC}$ ratio with $\mathrm{FVC}$ less than the lower limit of normal.

- Mixed obstructive and restrictive pattern as having an $\mathrm{FEV}_{1}$, an FVC, and an FEV1/FVC ratio all less than the lower limit of normal.

We used the $\mathrm{FEV}_{1}$ percent predicted to categorize such abnormalities as mild, moderate, moderately severe, severe, or very severe [Pellegrino et al. 2005].

Impulse Oscillometry

Many occupational lung diseases (e.g., chronic obstructive pulmonary disease, asthma) involve the small airways; however, this part of the lung is difficult to evaluate with standard spirometry. Oscillometry can better assess the effects of occupational exposures on the small airways. Studies have shown that oscillometry is a potentially important test in evaluating occupational hazards. There are no contraindications to the test as it is conducted using regular breathing and does not require a forceful exhalation [Smith et al. 2005]. Standard spirometry can be normal despite respiratory symptoms or evidence of small airways disease on lung biopsy that will show up on the oscillometry test [King et al. 2011; Oppenheimer et al. 2007]. Oscillometry results may complement standard spirometry.

We used a CareFusion Corporation impulse oscillometry machine to measure resistance (R), the energy required to propagate the pressure wave through the airways, and reactance $(\mathrm{X})$, which reflects the viscoelastic properties of the respiratory system. The impulse oscillometry testing machine sends sound waves called pressure oscillations at different frequencies (e.g., 5 Hertz and 20 Hertz) into the airways to measure how airways respond to these small pressure fluctuations. The test calculates the following:

- The airway resistance at different frequencies including $5 \operatorname{Hertz}\left(\mathrm{R}_{5}\right)$ and 20 Hertz $\left(\mathrm{R}_{20}\right)$

- The difference between $\mathrm{R}_{5}$ and $\mathrm{R}_{20}\left(\mathrm{R}_{5-20}\right)$

- The reactance at different frequencies including 5 Hertz $\left(\mathrm{X}_{5}\right)$

- Resonant frequency $\left(\mathrm{F}_{\text {res }}\right)$, which is the frequency where there is no airway reactance

- The total reactance $(\mathrm{AX})$ at all frequencies between 5 Hertz and the $\mathrm{F}_{\text {res }}$ 
We used several methods to analyze the impulse oscillometry results. The predicted values for $\mathrm{R}$ and $\mathrm{X}$ were based on sex and age according to reference values recommended by the manufacturer [Vogel and Smidt 1994]. $\mathrm{R}_{5}$ was considered abnormal (elevated) if the measured value was equal to or greater than 140 percent of the predicted $\mathrm{R}_{5} . \mathrm{X}_{5}$ was considered abnormal (decreased) if the value of the predicted $\mathrm{X}_{5}$ minus measured $\mathrm{X}_{5}$ was equal to or greater than 0.15 kilopascals per liter per second $(\mathrm{kPa} /(\mathrm{L} / \mathrm{s}))$. $\mathrm{R}_{5-20}$ values greater than 30\% were considered abnormal and evidence of frequency dependence [Smith 2015]. For the individual results already provided to participating fire fighters, we interpreted the test as normal if both the $\mathrm{R}_{5}$ and $\mathrm{X}_{5}$ were normal [Smith 2015]. We defined possible large (central) airways abnormality as a normal $\mathrm{X}_{5}$ and elevated $\mathrm{R}_{5}$ with no evidence of frequency dependence. We defined a possible small airways abnormality if there was evidence of frequency dependence and/or a decreased $\mathrm{X}_{5}$ with or without an elevated $\mathrm{R}_{5}$. We defined possible combined small (peripheral) and large (central) airways abnormality as a decreased $\mathrm{X}_{5}$ and elevated $\mathrm{R}_{5}$ with no evidence of frequency dependence.

In some of our analyses, we explored impulse oscillometry data comparing results with the upper limit of normal determined in previous populations studied following the attack on the World Trade Center [Friedman 2011]. The same parameters were assessed $\left(\mathrm{R}_{5}, \mathrm{R}_{20}, \mathrm{R}_{5-20}\right.$, and $\left.A X\right)$, using different units (centimeters of water per liter per second $\left.\left(\mathrm{cm} \mathrm{H}_{2} \mathrm{O} / \mathrm{L} / \mathrm{s}\right), 1 \mathrm{~cm} \mathrm{H}_{2} \mathrm{O}=0.0980665 \mathrm{kPA}\right) . \mathrm{R}_{5}$ greater than $3.96 \mathrm{~cm} \mathrm{H}_{2} \mathrm{O} / \mathrm{L} / \mathrm{s}$ was considered above the upper limit of normal and indicated total airways resistance. $\mathrm{R}_{20}$ greater than $3.20 \mathrm{~cm} \mathrm{H}_{2} \mathrm{O} \mathrm{cm} / \mathrm{L} / \mathrm{s}$ was considered above the upper limit of normal and indicated large airways resistance. $\mathrm{R}_{5-20}$ is referred to as the frequency dependence of resistance (FDR), and if greater than $0.76 \mathrm{~cm} \mathrm{H} \mathrm{H}_{2} \mathrm{O} / \mathrm{L} / \mathrm{s}$ was considered above the upper limit of normal and indicated small airways resistance. AX is referred to as the reactance area, and if greater than $3.6 \mathrm{~cm} \mathrm{H}_{2} \mathrm{O} \mathrm{cm} / \mathrm{L} / \mathrm{s}$ was considered above the upper limit of normal and indicated heterogeneity of small airways function.

\section{Bronchodilator Reversibility Testing for Impulse Oscillometry and Spirometry}

If a participant had abnormal impulse oscillometry or spirometry, we repeated both tests after the participant received a bronchodilator inhaler medication (i.e., albuterol), which can open the airways in some individuals (e.g., asthmatics). For oscillometry, we defined reversibility (improvement) after bronchodilator administration as a decrease of at least $20 \%$ of either $\mathrm{F}_{\text {res }}$ or $\mathrm{R}_{5}$ or a decrease of $40 \%$ for AX. For spirometry, we defined reversibility (improvement) as increases of at least $12 \%$ and 200 milliliters (mL) for either $\mathrm{FEV}_{1}$ or FVC after bronchodilator administration.

\section{Fractional Exhaled Nitric Oxide (FeNO)}

We used the Aerocrine Inc. NIOX MINO ${ }^{\circledR}$ device to measure the amount of nitric oxide in exhaled air. Nitric oxide is a gas that is produced by the airways, and elevated levels can be a sign of eosinophilic airway inflammation in asthma [Dweik et al. 2011]. In adults, fractional nitric oxide concentration in exhaled breath levels above $50 \mathrm{ppb}$ are considered elevated. In adults with asthma, elevated levels may indicate that their asthma is uncontrolled [Dweik et al. 2011].

\section{Results: NIOSH Pulmonary Function Testing}

Section C, Table 3 displays spirometry and impulse oscillometry results of fire fighters who participated in the medical survey. Forty-six $(98 \%)$ fire fighters completed the pulmonary function testing. Forty-five (98\%) of 46 firefighters had normal spirometry; one fire fighter had a restrictive pattern on spirometry. 
The mean percent predicted $\mathrm{FEV}_{1}$, percent predicted $\mathrm{FVC}$, and $\mathrm{FEV}_{1} / \mathrm{FVC}$ ratio among participating fire fighters indicated normal lung function for the group based on spirometry.

Twelve (26\%) of 47 fire fighters had impulse oscillometry test results interpreted as abnormal: five were consistent with a possible large airways abnormality, five consistent with a possible mixed small and large airways abnormality, and two consistent with a possible small airways abnormality. On impulse oscillometry, $26 \%$ of fire fighters had increased total airways resistance or $\mathrm{R}_{5}$ on impulse oscillometry. Although $37 \%$ of participating fire fighters had increased large airways resistance or $\mathrm{R}_{20}$, none of these fire fighters had obstructive patterns on spirometry. Impulse oscillometry results indicated small airways abnormalities in $17 \%$ of fire fighters on the basis of elevated FDR $\left(\mathrm{R}_{5-20}\right)$, and $41 \%$ of fire fighters on the basis of reactance area (AX). Six $(60 \%)$ of 10 fire fighters who took a bronchodilator showed significant improvement in impulse oscillometry. Three $(7 \%)$ fire fighters had exhaled nitric oxide tests interpreted as elevated, two of whom reported asthma-like symptoms.

Fire fighters with cough and wheeze that began during or within days of the response were more likely to have elevated FDR compared with fire fighters with no symptoms (30\% vs. 8\%; 50\% vs. 13\%, respectively: $P<0.05)$ beginning during or within days of the response.

\section{Method: Occupational Health Provider Consultation}

A NIOSH spirometry technician along with a one of this department's fire chiefs met with the occupational health provider that performed the annual spirometry for most of this department's fire fighters.

\section{Results: Occupational Health Provider Consultation}

Our review of the department's annual spirometry testing determined that many tests contained positive zero flow errors resulting in tests that were not suitable for clinical decision making. Errors of this type can occur in flow spirometers when there is airflow while the spirometer is being zeroed before the test session. The numbers generated by trials with positive zero flow errors cannot be used, as the reported values are erroneously high. Technicians need to recognize this type of error in real time in order to rezero the equipment to correct the error as spirometry testing incurring this error are not suitable to use for clinical decision making.

It was unlikely that the occupational health provider was able to identify these errors in real time as the small monitor of the handheld flow spirometers used by this provider to conduct spirometry testing would make it difficult to see. In order for spirometry technicians to see when a zero flow error is occurring, a computer monitor should be used in conjunction with the handheld device to allow for improved visualization of the testing conducted. We provided this information to the occupational health provider during our meeting and provided them with the Spirometry Testing in Occupational Health Programs: Best Practices for Healthcare Professionals document [OSHA 2013].

\section{Discussion}

Chemical fires present a challenge for exposure reconstruction due to their unpredictable mixtures and unknown products of combustion. The issue is compounded here by (1) unknown original substances involved, (2) incomplete Tier II chemical inventory, (3) improper labeling, and (4) limited post-event 
sampling. Due to these factors, the exact chemicals encountered by responding fire fighters will likely remain unknown.

The only objective data regarding potential exposures were from limited sampling that showed an alkaline substance to be present in four types of samples, (1) solid residual vat waste, (2) water, (3) crystals formed on contaminated gear, and (4) litmus strips on turnout gear exterior. Many alkaline substances can be an irritant to any surface it contacts (including the eyes, nose, mouth, and respiratory system) resulting in the symptoms reported by fire fighters. However, these same symptoms of cough and dry/scratchy throat could be caused by any number of other types of chemical irritants or caustic substances that may have been in the disposal vat, produced during the fire, or present elsewhere in the building. Two fire fighters with persistent respiratory symptoms of dry cough and throat irritation who were evaluated by a pulmonologist were diagnosed with "exacerbation of pre-existing asthma - cause undetermined." Since no fire fighter developed clinical symptoms or radiological evidence of chemical pneumonitis (that may have further narrowed down the list of potential causative agents), no further determination can be made [ALA 2018; Brooks 2013]. Previous studies of structural fire fighters have demonstrated potential for exposure to a variety of substances during responses to routine residential fires such as cyanide produced by the combustion of upholstery padding, polyaromatic hydrocarbons (the main component of soot) of which some have been identified as potential carcinogens, etc. [Fent et al. 2018; Jones et al. 1987].

Fire fighters reported a variety of symptoms that began during or shortly following the response, some of which persisted and were ongoing at the time of the first and second site visits. The most commonly reported symptoms were coughing, metallic taste, fatigue, and throat irritation. These symptoms began during or shortly following the response, suggesting the primary insult was an inhalational exposure to irritants affecting mucous membranes of the eyes, nose, mouth, and upper airways. Symptom prevalence decreased over time. During our first site visit (about one month after the incident), 13 fire fighters reported persistent symptoms that began during or shortly after the incident. Cough was the most common symptom reported, followed by shortness of breath, fatigue and throat irritation. During our second site visit (about 4 months after incident), seven fire fighters reported ongoing respiratory symptoms, including cough, trouble breathing, wheeze, chest tightness, being awoken by cough, or being awoken by shortness of breath. Fire fighters with ongoing symptoms should continue to follow up with their healthcare provider.

Fire fighters were diagnosed with the following conditions after the fire: sinusitis, pneumonia, reactive airways dysfunction syndrome (RADS), and tracheobronchomalacia. Although the association between the fire response and the diagnosis of some of these conditions is unclear, others may be more plausible given the timing of the onset of condition and the potential chemicals that may have been present. Many chemicals used in general manufacturing may act as either respiratory irritants and some may act as sensitizers. For example, RADS is caused by certain chemical exposures and is characterized by asthmalike symptoms and airway hyperresponsiveness that may persist for a prolonged period [Shakeri et al. 2008]. The diagnosis of RADS is based upon a history of exposure to an irritant preceding the onset of acute respiratory symptoms, and persistent airway obstruction and/or hyperresponsiveness. RADS has been associated with a decreased quality of life and increased depression and anxiety [Malo et al. 2009]. Employees with persistent respiratory symptoms, particularly cough, shortness of breath, or wheeze 
should be assessed for RADS and evidence of reversible airflow limitation (e.g., spirometry with bronchodilator reversibility or positive non-specific bronchoprovocation challenge). Screening questions for occupational asthma have been developed and validated [ECRHS 2014]. Use of these screening questions in conjunction with spirometry can help in early identification of fire fighters who have developed RADS or work-related asthma. The majority of patients with RADS improve over time, although many continue to have respiratory symptoms for at least a year and have physiologic abnormalities such as bronchial hyperresponsiveness for several years [Bardana 1999; Brooks et al. 1985]. Spirometry can be used to help detect and follow individuals with asthma. Spirometry can show if air is exhaled from the lungs more slowly than normal (i.e., obstructive abnormality) or if the amount of air exhaled is smaller than normal (i.e., restrictive abnormality). In asthma, there is intermittent airways obstruction, which is reversible after treatment with bronchodilator medications (e.g., albuterol). While there were no obstructive patterns identified by spirometry, nearly three times as many fire fighters reported current physician-diagnosed asthma than expected. In addition, more than three times as many fire fighters reported wheeze than expected. Three fire fighters had high exhaled nitric oxide, a marker of allergic airways inflammation, which can be elevated in persons with uncontrolled asthma. No fire fighters were diagnosed with asthma since the chemical fire response, and some reported a diagnosis of asthma before becoming a fire fighter. Although exposures related to their occupation as a fire fighter might not have caused asthma, it remains possible their condition was made worse by exposures during fire responses.

Although NIOSH-conducted spirometry was abnormal for only one participant, 12 (26\%) fire fighters had impulse oscillometry test results interpreted as abnormal. Using impulse oscillometry, we found an association between small airways abnormalities and respiratory symptoms, but we cannot determine if all abnormalities were related to the response. Spirometry and impulse oscillometry measure different things. Spirometry assesses airflow and is the breathing test typically used to screen for occupational lung disease. Impulse oscillometry assesses the airways response to a sound or pressure wave and has not commonly been used to screen for occupational lung disease. In general, during the impulse oscillometry test, a small pressure impulse (sound wave) is imposed upon the inspiratory and expiratory airflow during normal tidal breathing. This pressure wave causes a disturbance in the airflow and pressure, and the response of the airways (i.e., change in pressure to change in flow) is a measure of the resistance to airflow in the airways [Desiraju and Agrawal 2016]. Impulse oscillometry may be useful as an indirect measure of airflow obstruction and helpful in individuals not able to perform forced breathing maneuvers that are required during the spirometry test. The impulse oscillometry test has been used for many years to measure changes in the airways of children with lung problems such as asthma and cystic fibrosis [Komarow et al. 2011; Schulze et al. 2016; Shi et al. 2012; Song et al. 2008]. More recently, impulse oscillometry has been used to investigate lung problems in adults exposed to dust or chemicals, such as World Trade Center emergency responders and soldiers returning from deployment overseas [Berger et al. 2013; Oppenheimer et al. 2007; Weinstein et al. 2016]. Over the years, researchers have developed reference (predictive) equations for different populations of children for oscillometry [de Assumpção et al. 2016; Lee et al. 2012; Malmberg et al. 2002; Park et al. 2011]. For adults, there are fewer reference equations available for oscillometry [Newbury et al. 2008; Schulz et al. 2013; Vogel and Smidt 1994]. The predicted values we used for oscillometry measures were based on 
gender and age according to references values recommended by the manufacturer. Unlike predictive equations used for spirometry, the impulse oscillometry reference equations we used did not take into account height, race, or smoking status [Vogel and Smidt 1994].

Review of the department's past spirometry showed that many of these tests contained procedural testing errors. The majority of these testing errors would likely have been identified by the technicians and corrected if they had a larger display making it easier for them to see when these testing errors occurred in real time. The type of error noted on the spirometry results, called a positive zero flow error, is one that compromises the validity of the result to the point where it is unusable for any type of clinical decision- making. A spirometry test with this type of error should be immediately redone once the error is corrected to provide a result a healthcare provider can use to assess lung function and base treatment decisions. The occupational health provider has the expertise and training required to identify and correct these errors, and is committed to making the necessary equipment upgrades to do so. Discussions with the contractor revealed that all spirometry tests are reviewed by an occupational medicine physician to confirm interpretation of the test before they are reported to the fire department. This review does not extend to an assessment of the technical quality of each test.

A strong medical surveillance program will allow for early identification of employees who may be developing lung disease (e.g., asthma, COPD) and help prioritize interventions. The program should include an annual questionnaire for health symptoms and evaluating spirometry testing over time. In adults, FVC and FEV 1 are expected to decline by approximately $30 \mathrm{~mL}$ each year, but a 15\% decline in approximately one year is more than expected. Excessive decline in FVC or FEV 1 could be due to work-related lung disease, or other factors such as the spirometry equipment, test subject or technician technique, or non-work-related illness affecting results. It is important to monitor the change in lung function over time in employees participating in the medical surveillance program, and investigate excessive decline in FVC or FEV 1 to address the possibility of work-related lung disease, and rule it out or remove that employee from potential respiratory hazards at work.

Our evaluation did not identify a single (unique) medical condition among the affected fire fighters who reported persistent symptoms during either of our site visits. Each medical condition has its own group of symptoms, cause, disease progression, and treatment recommendations. Without a common diagnosis among the fire fighters with persistent symptoms, there is not adequate information on which to base any recommendations for additional medical monitoring beyond the annual spirometry testing the department is already doing. However, the department may want to consider adding a respiratory screening questionnaire to its annual spirometry testing. This may help in faster identification of new lung issues in their staff by having symptom reports to evaluate on their own and in conjunction with the spirometry test results. It is not uncommon for patients to experience subjective symptoms of shortness of breath, cough, or wheeze before they show a large drop on their spirometry parameters as described above. Individuals reporting symptoms showing a normal spirometry test may be referred to their primary care providers for more in-depth testing or presumptive treatment.

\section{Conclusions}

The exact exposures to fire fighters participating in this response could not be determined. Company A's incomplete documentation and labeling practices, the nature of these types of fires, along with the 
minimal sampling conducted after the fire contributed to these unquantifiable and unidentifiable exposures. Many fire fighters who participated in the response reported symptoms during or shortly after the response. Most fire fighters who developed respiratory symptoms during or within days of the January 2018 response reported resolution of symptoms by May 2018.

While the department's goal of performing medical screening after the response was appropriate, procedural testing errors limited the usefulness of many of these tests. Recommendations intended to assist the department in improving future screening activities and the existing medical surveillance program are provided in this report. 


\section{Section C: Tables}

Table 1. Laboratory results from samples collected from the site of the fire, January 2018

\begin{tabular}{|c|c|c|c|c|c|}
\hline \multirow[t]{2}{*}{ Compound } & \multicolumn{3}{|c|}{ Matrix: water, mg/L } & \multicolumn{2}{|c|}{ Matrix: solid, mg/kg } \\
\hline & Result & Reporting limit* & NPDWR & Result & Reporting limit* \\
\hline Antimony & ND & 2.5 & 0.006 & ND & 2.2 \\
\hline Arsenic & ND & 0.25 & 0.010 & 0.83 & 0.45 \\
\hline Beryllium & ND & 0.25 & 0.0040 & ND & 0.22 \\
\hline Cadmium & ND & 0.25 & 0.0050 & ND & 0.45 \\
\hline Chromium & 5.2 & 0.50 & 0.10 & 0.51 & 0.45 \\
\hline Copper & 7.0 & 0.50 & 1.3 & 0.67 & 0.45 \\
\hline Lead & 2.6 & 0.50 & 0.015 & ND & 2.2 \\
\hline Mercury & 0.0015 & 0.0010 & 0.0020 & ND & 0.07 \\
\hline Nickel & 5.2 & 1.3 & NA & ND & 1.1 \\
\hline Selenium & 2.9 & 0.50 & 0.050 & ND & 0.89 \\
\hline Silver & ND & 0.35 & 0.10 & ND & 0.45 \\
\hline Thallium & ND & 1.0 & 0.0020 & ND & 0.89 \\
\hline Zinc & 29 & 2.5 & 5.0 & ND & 2.2 \\
\hline $\mathrm{pH} \dagger$ & 13 & NA & $6.5-8.5$ & 13 & NA \\
\hline Total cyanide & 0.58 & 0.050 & 0.20 & ND & 1.1 \\
\hline Chloride & 370 & 200 & NA & 200 & 100 \\
\hline Nitrogen $\ddagger$ & 1,100 & 50 & 1.0 & 610 & 52 \\
\hline Sulfate & 3,000 & 2,500 & 250 & 2,100 & 1,400 \\
\hline Total solids & NA & NA & $0.3 \mathrm{NTU}$ & $87 \%$ & $0.10 \%$ \\
\hline
\end{tabular}

$\mathrm{mg} / \mathrm{L}=$ Milligrams per liter

$\mathrm{mg} / \mathrm{kg}=$ Milligrams per kilogram

NPDWR = National Primary Drinking Water Regulations, the legally enforceable primary standards and treatment techniques that apply to public water systems.

$\mathrm{ND}=$ Not detected

NA $=$ Not applicable

NTU = Nephelometric turbidity unit

*Reporting limit, a value reported by the laboratory at which an instrument can accurately measure an analyte at a specific concentration. The reporting limit includes any adjustments from dilutions, concentrations, or moisture content (where applicable).

$\mathrm{tpH}$ is a scientific unit of scale from 0 (extremely acid) to 14 (extremely basic).

$\ddagger$ Nitrogen results also include nitrogen in the form of nitrates and nitrites.

C-1 
Table 2. Demographics of participants, second site visit, May $2018(n=47)$

\begin{tabular}{lc}
\hline Demographics & $\mathrm{n}(\%)$ \\
\hline Male & $46(98 \%)$ \\
Age (years), median (range) & $46(27-59)$ \\
\hline Race and ethnicity & \\
$\quad$ White & $46(98 \%)$ \\
$\quad$ Spanish, Hispanic or Latino & $1(2 \%)$ \\
\hline Smoke status & \\
$\quad$ Never & $36(77 \%)$ \\
$\quad$ Current & $2(4 \%)$ \\
$\quad$ Former & $9(19 \%)$ \\
\hline Fire department tenure (years), median (range) & $16(1-38)$ \\
Total firefighter tenure (years), median (range) & $21(2-41)$ \\
\hline
\end{tabular}

Table 3. Selected symptoms among NIOSH questionnaire participants, May $2018(n=47)$

\begin{tabular}{lccc}
\hline Symptom & $\begin{array}{c}\text { Last } 12 \text { months } \\
\mathrm{n}(\%)\end{array}$ & $\begin{array}{c}\text { During or shortly } \\
\text { following fire response* } \\
\mathrm{n}(\%)\end{array}$ & $\begin{array}{c}\text { During survey } \\
\text { (May-June 2018) } \\
\mathrm{n}(\%)\end{array}$ \\
\hline Cough & $29(62 \%)$ & $20(43 \%)$ & $4(9 \%)$ \\
Trouble breathing & $15(32 \%)$ & $8(17 \%)$ & $4(9 \%)$ \\
Wheeze & $15(32 \%)$ & $6(13 \%)$ & $1(2 \%)$ \\
Awoken by cough & $12(26 \%)$ & $6(13 \%)$ & $1(2 \%)$ \\
Chest tightness & $6(13 \%)$ & $3(6 \%)$ & $1(2 \%)$ \\
Asthma attack & $6(13 \%)$ & $1(2 \%)$ & 0 \\
Awoken by shortness of breath & $3(6 \%)$ & $3(6 \%)$ & $1(2 \%)$ \\
Fatigue & $17(36 \%)$ & $14(30 \%)$ & $8(17 \%)$ \\
Throat irritation & $16(34 \%)$ & $13(28 \%)$ & $3(6 \%)$ \\
Headaches & $15(32 \%)$ & $8(17 \%)$ & $5(11 \%)$ \\
Skin symptoms & $13(28 \%)$ & $7(15 \%)$ & $4(9 \%)$ \\
Eyes burning & $10(21 \%)$ & $2(4 \%)$ & $1(2 \%)$ \\
\hline
\end{tabular}

*Includes 'during,' 'night of,' and 'day or days after' the fire response in January 2018 
Table 4. Medical testing results among survey participants, second visit, May $2018(n=46)$

\begin{tabular}{|c|c|}
\hline Spirometry results & $\mathrm{n}(\%)$ \\
\hline Normal & $45(98 \%)$ \\
\hline Obstruction & 0 \\
\hline Restriction & $1(2 \%)$ \\
\hline Spirometry values & Mean (range) \\
\hline$\% F E V_{1}$ & $101.5(75.6-134.5)$ \\
\hline$\% F V C$ & $102.8(76.6-132.6)$ \\
\hline $\mathrm{FEV}_{1} / \mathrm{FVC}$ & $78.0(61.7-94.1)$ \\
\hline $\begin{array}{l}\text { Exhaled nitric oxide (FeNO), } \\
\text { in parts per billion (ppb) }\end{array}$ & $26(7-88)$ \\
\hline FeNO > 50 ppb, n (\%) & $3(7 \%)$ \\
\hline Impulse oscillometry results & $\mathrm{n}(\%)$ \\
\hline Normal & $34(74 \%)$ \\
\hline Small airways abnormality & $2(4 \%)$ \\
\hline Large airways abnormality & $5(11 \%)$ \\
\hline $\begin{array}{l}\text { Small and large airways } \\
\text { abnormality }\end{array}$ & $5(11 \%)$ \\
\hline Impulse oscillometry results* & n (\%) \\
\hline $\mathrm{R}_{5}>3.96 \dagger$ & $12(26 \%)$ \\
\hline $\mathrm{R}_{20}>3.20 \ddagger$ & $17(37 \%)$ \\
\hline $\mathrm{R}_{5-20}>0.76 \S$ & $8(17 \%)$ \\
\hline$A X>3.6 \pi$ & $19(41 \%)$ \\
\hline
\end{tabular}

${ }^{*}$ Results compared with upper limit of normal $\left(\mathrm{cm} \mathrm{H}_{2} \mathrm{O} / \mathrm{L} / \mathrm{s}\right)$

†Total airways resistance

‡Large airways resistance

$\S S m a l l$ airways resistance or frequency dependence of resistance

ॠHeterogeneity of small airways function or reactance area 
Table 5. Adjusted comparisons of symptoms and self-reported physician diagnosis among survey participants to U.S. populations, second site visit, May $2018(n=47)$

\begin{tabular}{lccc}
\hline Symptom/diagnosis & Observed & Expected & SMR* $^{\star}$ \\
\hline Shortness of breath & 3 & 6.1 & $0.5(0.2-1.4)$ \\
Usual cough & 2 & 2.3 & $0.9(0.2-3.1)$ \\
Wheeze & 15 & 4.4 & $\mathbf{3 . 4}(\mathbf{2 . 1 - 5 . 7 )}$ \\
Chronic bronchitis & 2 & 1.6 & $1.3(0.4-4.7)$ \\
Ever asthma & 11 & 5.8 & $\mathbf{1 . 9 ( 1 . 1 - 3 . 4 )}$ \\
Current asthma & 8 & 2.8 & $\mathbf{2 . 8 ( 1 . 4 - 5 . 6 )}$ \\
\hline
\end{tabular}

*Standardized morbidity ratio

We used the most recent NHANES survey available for each comparison.

Adjusted for sex, race/ethnicity, age, and smoking categories.

95\% confidence intervals (Cls) that include one are statistically significantly different from comparisons with U.S. adult population and are shown in bold. 


\section{Section D: References}

\section{Respiratory Health Effects}

ALA [2018]. Cryptogenic organizing pneumonia (COP). American Lung Association, https://www.lung.org/lung-health-and-diseases/lung-disease-lookup/cryptogenic-organizingpneumonia/.

Bardana EJ [1999]. Reactive airways dysfunction syndrome (RADS): guidelines for diagnosis and treatment and insight into likely prognosis. Ann Allergy Asthma Immunol 83(6 Pt 2):583-586, https://doi.org/10.1016/s1081-1206(10)62876-1.

Berger KI, Reibman J, Oppenheimer BW, Vlahos I, Harrison D, Goldring RM [2013]. Lessons from the World Trade Center disaster: airway disease presenting as restrictive dysfunction. Chest 144(1):249_ 257, https://doi.org/10.1378/chest.12-1411.

Brooks SM, Weiss MA, Bernstein IL [1985]. Reactive airways dysfunction syndrome (RADS). Persistent asthma syndrome after high level irritant exposures. Chest 88(3):376-384, https://doi.org/10.1378/chest.88.3.376.

Brooks SM [2013]. Reactive airways dysfunction syndrome and considerations of irritant-induced asthma. J Occup Environ Med 55(9):1118-1120, https://doi.org/10.1097/JOM.0b013e318229a679. Burney PGJ, Chinn S [1987]. Developing a new questionnaire for measuring the prevalence and distribution of asthma. Chest 91(6 Suppl):79S-83S, https://doi.org/10.1378/chest.91.6.79s.

Burney PG, Laitinen LA, Perdrizet S, Huckauf H, Tattersfield AE, Chinn S, Poisson N, Heeren A, Britton JR, Jones T [1989]. Validity and repeatability of the IUATLD (1984) bronchial symptoms questionnaire: an international comparison. Eur Respir J 2(10):940-945.

Burney PGJ, Luczynska C, Chinn S, Jarvis D [1994]. The European community respiratory health survey. Eur Respir J 7(5):954-960, https://doi.org/10.1183/09031936.94.07050954.

Centers for Disease Control and Prevention [1996]. Third national health and nutrition examination survey, 1988-1994, NHANES III Examination Data File [CDROM]. Hyattsville, Maryland: U.S. Department of Health and Human Services, Centers for Disease Control and Prevention. (Public use data file documentation No. 76300.)

Centers for Disease Control and Prevention [2018]. National Health and Nutrition Examination Survey Data, [2007-2012]. Hyattsville, MD: U.S. Department of Health and Human Services, Centers for Disease Control and Prevention, National Center for Health Statistics, https://wwwn.cdc.gov/nchs/nhanes/default.aspx.

ECRHS [2014]. Questionnaires, protocols and instructions. European Community Respiratory Health Survey, http://www.ecrhs.org/Quests.htm.

King MS, Eisenberg R, Newman JH, Tolle JJ, Harrell FE Jr, Nian H, Ninan M, Lambright ES, Sheller JR, Johnson JE, Miller RF [2011]. Constrictive bronchiolitis in soldiers returning from Iraq and Afghanistan. N Engl J Med 365(3):222-230, https://doi.org/10.1056/nejmoa1101388. 
Malmberg LP, Pelkonen A, Poussa T, Pohianpalo A, Haahtela T, Turpeinen M [2002]. Determinants of respiratory system input impedance and bronchodilator response in healthy Finnish preschool children. Clin Physiol Funct Imaging 22(1):64-71, https://doi.org/10.1046/j.1475-097X.2002.00396.x.

Malo JL, L'archevêque J, Castellanos L, Lavoie K, Ghezzo H, Maghni K [2009]. Long-term outcomes of acute irritant-induced asthma. Am J Respir Crit Care Med 179(10):923-928, https://doi.org/10.1164/rccm.200810-1550oc.

Shakeri MS, Dick FD, Ayers JG [2008]. Which agents cause reactive airway dysfunction syndrome (RADS)? A systematic review. Occup Med 58(3):205-211, https://doi.org/10.1093/occmed/kqn013.

Weinstein DJ, Hull JE, Ritchie BL, Hayes JA, Morris MJ [2016]. Exercise-associated excessive dynamic airway collapse in military personnel. Ann Am Thorac Soc 13(9):1476-1482,

https://doi.org/10.1513/AnnalsATS.201512-790OC.

\section{Spirometry Components and Population Based Spirometry Data}

de Assumpção MS, Gonçalves RM, Martins R, Bobbio TG, Schivinski CI [2016]. Reference equations for impulse oscillometry system parameters in healthy Brazilian children and adolescents. Respir Care 61(8):1090-1099, https://doi.org/10.4187/respcare.04226.

Desiraju K, Agrawal A [2016]. Impulse oscillometry: the state-of-art for lung function testing. Lung India 33(4):410-416, https://dx.doi.org/10.4103\%2F0970-2113.184875.

Dweik RA, Boggs PB, Erzurum SC, Irvin CG, Leigh MW, Lundberg JO, Olin AC, Plummer AL, Taylor DR; American Thoracic Society Committee on Interpretation of Exhaled Nitric Oxide Levels (FENO) for Clinical Applications [2011]. An official ATS clinical practice guideline: interpretation of exhaled nitric oxide levels (FENO) for clinical applications. Am J Respir Crit Care Med 184(5):602-615, https://doi.org/10.1164/rccm.9120-11ST.

Friedman SM, Maslow CB, Reibman J, Pillai PS, Goldring RM, Farfel MR, Stellman SD, Berger KI [2011]. Case-control study of lung function in World Trade Center health registry area residents and workers. Am J Respir Crit Care Med 184(5):582-589, https://doi.org/10.1164/rccm.201011-1909oc.

Hankinson JL, Odencrantz JR, Fedan KB [1999]. Spirometric reference values from a sample of the general U.S. population. Am J Respir Crit Care Med 159(1):179-187,

https://doi.org/10.1164/ajrccm.159.1.9712108.

Komarow HD, Myles IA, Uzzaman A, Metcalfe DD [2011]. Impulse oscillometry in the evaluation of diseases of the airways in children. Ann Allergy Asthma Immunol 106(3):191-199, https://dx.doi.org/10.1016\%2Fj.anai.2010.11.011.

Lee JY, Seo JH, Kim HY, Jung YH, Kwon JW, Kim BJ, Kim HB, Lee SY, Jang GC, Song DJ, Kim WK, Shim JY, Kim HJ, Shin YJ, Park JW, Cho SH, Lee JS, Hong SJ [2012]. Reference values of impulse oscillometry and its utility in the diagnosis of asthma in young Korean children. J Asthma 49(8):811816, https://doi.org/10.3109/02770903.2012.716472. 
Miller MR, Hankinson J, Brusasco V, Burgos F, Casaburi R, Coates A, Crapo R, Enright P, van der Grinten CP, Gustafsson P, Jensen R, Johnson DC, MacIntyre N, McKay R, Navajas D, Pedersen OF, Pellegrino R, Viegi G, Wanger J, ATS/ERS Task Force [2005]. Standardisation of spirometry. Eur Respir J 26(2):319-338, https://doi.org/10.1183/09031936.05.00034805.

Newbury W, Crockett A, Newbury J [2008]. A pilot study to evaluate Australian predictive equations for the impulse oscillometry system. Respirology 13(7):1070-1075, https://doi.org/10.1111/j.14401843.2008.01375.x.

Oppenheimer BW, Goldring RM, Herberg ME, Hofer IS, Reyfman PA, Liautaud S, Rom WN, Reibman J, Berger KI [2007]. Distal airway function in symptomatic subjects with normal spirometry following World Trade Center dust exposure. Chest 132(4):1275-1282, https://doi.org/10.1378/chest.07-0913.

OSHA [2013]. Spirometry testing in occupational health programs: Best practices for healthcare providers. Washington, DC: U.S. Department of Labor, Occupational Safety and Health. OSHA $3637-$ 03 2013. https://www.osha.gov/Publications/OSHA3637.pdf.

Park JH, Yoon JW, Shin YH, Jee HM, Wee YS, Chang SJ, Sim JH, Yum HY, Han MY [2011]. Reference values for respiratory system impedence using impulse oscillometry in healthy preschool children. Korean J Pediatr 54(2):64-68, https://dx.doi.org/10.3345\%2Fkjp.2011.54.2.64.

Pellegrino R, Viegi G, Brusasco V, Crapo RO, Burgos F, Casaburi R, Coates A, van der Grinten CP, Gustafsson P, Hankinson J, Jensen R, Johnson DC, MacIntyre N, McKay R, Miller MR, Navajas D, Pedersen OF, Wanger J [2005]. Interpretative strategies for lung function tests. Eur Respir J 26(5):948968, https://doi.org/10.1183/09031936.05.00035205.

Schulz H, Flexeder C, Behr J, Heier M, Holle R, Huber RM, Jörres RA, Nowak D, Peters A, Wichmann HE, Heinrich J, Karrasch S, KORA Study Group [2013]. Reference values of impulse oscillometric lung function indices in adults of advanced age. PLoS One 8(5):e63366, https://dx.doi.org/10.1371\%2Fjournal.pone.0063366.

Schulze J, Biedebach S, Christmann M, Herrmann E, Voss S, Zielen S [2016]. Impulse oscillometry as a predictor of asthma exacerbations in young children. Respiration 91(2):107-114, https://doi.org/10.1159/000442448.

Shi Y, Aledia AS, Tatavoosian AV, Vijayalakshmi S, Galant SP, George SC [2012]. Relating small airways to asthma control by using impulse oscillometry in children. Allergy Clin Immunol 129(3):671678, https://doi.org/10.1016/j.jaci.2011.11.002.

Smith HJ, Reinhold P, Goldman MD [2005]. Forced oscillation technique and impulse oscillometry. In: Gosselink R, Stam H, eds. European respiratory monograph 31: lung function testing. Vol. 10. Wakefield, UK: European Respiratory Society Journals, pp. 72-105, https://doi.org/10.1183/1025448x.00031005. 
Smith HJ (Hans-Juergen.Smith@CareFusion.com) [2015]. Questions about impulse oscillometry. Email of December 9, 2015, from Hans-Juergen Smith, CareFusion, to Rachel Bailey (feu2@cdc.gov), Respiratory Health Division, National Institute for Occupational Safety and Health, Centers for Disease Control and Prevention, Department of Health and Human Services.

Song TW, Kim KW, Kim ES, Park JW, Sohn MH, Kim KE [2008]. Utility of impulse oscillometry in young children with asthma. Pediatr Allergy Immunol 19(8):763-768, https://doi.org/10.1111/j.13993038.2008.00734.x.

Vogel J, Smidt U [1994]. Impulse oscillometry. Analysis of lung mechanics in general practice and clinic, epidemiological and experimental research. 1st ed. Frankfurt: PMIVerlagsgruppe.

\section{Components of Fire Smoke}

Fent KW, Evans DE, Babik K, Striley C, Bertke S, Kerber S, Smith D, Horn GP [2018]. Airborne contaminants during controlled residential fires. J Occup Environ Hyg 15(5):399_412, https://doi.org/10.1080/15459624.2018.1445260.

Jones J, McMullen MJ, Dougherty J [1987]. Toxic smoke inhalation: cyanide poisoning in fire victims. Am J Emerg Med 5(4):318-321, https://doi.org/10.1016/0735-6757(87)90360-3.

\section{General}

Ferris BG [1978]. Epidemiology standardization project. Am Rev Respir Dis 118(Suppl):1-53. 
Delivering on the Nation's promise:

Promoting productive workplaces through safety and health research

Get More Information

Find NIOSH products and get answers to workplace safety and health questions:

1-800-CDC-INFO (1-800-232-4636) | TT: 1-888-232-6348

CDC/NIOSH INFO: $\underline{c d c . g o v / i n f o}$ | cdc.gov/niosh

Monthly NIOSH eNews: $\underline{c d c . g o v / n i o s h / e N e w s}$ 